\title{
Correction
}

\section{Correction: Perez-Alvarez et al., Structural and Functional Plasticity of Astrocyte Processes and Dendritic Spine Interactions}

In the article "Structural and Functional Plasticity of Astrocyte Processes and Dendritic Spine Interactions" by Alberto Perez-Alvarez, Marta Navarrete, Ana Covelo, Eduardo D. Martin, and Alfonso Araque, which appeared on pages 12738-12744 of the September 17, 2014 issue, a third affiliation was accidentally added to the last author. The corrected author list is as follows: "Alberto Perez-Alvarez, ${ }^{1,2 \star}$ Marta Navarrete, ${ }^{1 \star}$ Ana Covelo, ${ }^{1}$ Eduardo D. Martin, ${ }^{3}$ and Alfonso Araque ${ }^{1,4}$. The last author's corrected affiliation is as follows: ${ }^{1}$ Instituto Cajal, CSIC, 28002 Madrid, Spain and ${ }^{4}$ Department of Neuroscience, University of Minnesota, Minneapolis, Minnesota 55455.

DOI:10.1523/JNEUROSCI.3913-14.2014 